\title{
Correction to: Hypergeometric Polynomials, Hyperharmonic Discrete and Continuous Expansions: Evaluations, Interconnections, Extensions
}

\author{
Cecilia Coletti, Federico Palazzetti, Roger W. Anderson, \\ Vincenzo Aquilanti, Noelia Faginas-Lago, and Andrea Lombardi
}

\begin{abstract}
Correction to:
Chapter "Hypergeometric Polynomials, Hyperharmonic Discrete and Continuous Expansions: Evaluations, Interconnections, Extensions" in: S. Misra et al. (Eds.): Computational Science and Its Applications - ICCSA 2019, LNCS 11624, https://doi.org/10.1007/978-3-030-24311-1_34
\end{abstract}

The original version of this chapter was inadvertently published without two authors who contributed to the chapter also. The missing authors were Noelia Faginas-Lago and Andrea Lombardi. Their names and affiliations have now been added and the correct sequence of the authors is: Cecilia Coletti, Federico Palazzetti, Roger W. Anderson, Vincenzo Aquilanti, Noelia Faginas-Lago and Andrea Lombardi. 